\title{
Hydrated phases and pore solution composition in cement- solidified saltstone waste forms
}

\author{
K.A. Snyder ${ }^{1, a}$, P.E. Stutzman ${ }^{1}$, J. Philip ${ }^{2}$, and D. Esh ${ }^{2}$ \\ ${ }^{1}$ National Institute of Standards and Technology, Gaithersburg, MD USA \\ ${ }^{2}$ U.S. Nuclear Regulatory Commission, Washington, D.C. USA
}

\begin{abstract}
The mineral phases and pore solution composition of hydrated cementsolidified synthetic saltstone waste forms are quantified using thermogravimetric analysis, quantitative X-ray powder diffraction, and inductively coupled plasma atomic emission spectroscopy. Although the synthetic waste contained additional sulfate, the overall chemistry of the system suppressed the formation of sulfate-bearing mineral phases. This was corroborated by the pore solution analysis that indicated very high sulfur concentrations. After one year of hydration, the mineral phases present and the composition of the pore solution are stable, and are generally consistent with expectations based on the hydration of high volume portland cement replacement mixtures.
\end{abstract}

\section{Introduction}

Some strategies for cement solidified waste use cementitious mixtures composed of very little portland cement to stabilize a concentrated aqueous waste solution containing radionuclides. In one example, the concentrated salt solution (supernate) and crystallized saltcake are to be stabilized in a cementitious saltstone grout [1] formulated by the Savannah River National Laboratory (SRNL) for final disposal in vaults at the Saltstone Disposal Facility (SDF) at Savannah River Site (SRS). These grout mixtures may contain as little as $5 \%$ portland cement, with the remainder of the binder being equal portions of fly ash and slag. Moreover, the supernate contains, among other salts, sodium hydroxide, sodium nitrate, and sodium nitrite [2]. Therefore, not only is this solution highly alkaline, it contains nitrates and nitrites, which are typically not found in the thermodynamic databases for the service life prediction of cementitious systems. Service life performance predictions depend upon accurately characterizing the transport properties and the pore solution chemistry, but there are no models for predicting the hydrated phases and the pore solution composition of these systems.

To support these thermodynamic calculations, a study was conducted to identify and quantify the mineral composition of a set of pastes that mimic the type of saltstone grout being developed at SRNL. These pastes contained the same cement, slag, and fly ash used at SRNL, and the "mix water" was an approximation to the SRNL surrogate waste for physical testing (SWPT) [1] that contains no radionuclides. The raw materials and the hardened pastes were characterized using quantitative X-ray powder diffraction (QXRD) and thermogravimetric analysis (TGA) to provide

\footnotetext{
a e-mail: kenneth.snyder@nist.gov
} 
direct estimates of the bulk mineralogical composition. The pore solution composition was characterized by elemental analysis using inductively-coupled plasma optical emission spectroscopy.

\section{Experimental Plan}

The mixture designs were divided between two water:cementitious mass ratios $(\mathrm{w} / \mathrm{cm})$, two different binder mixtures, and the use of either water or a surrogate waste solution. As a reference, the grout formulated by SRNL [2] had a $w / \mathrm{cm}$ (neglecting the dissolved solids in the SWPT) of 0.60. At this water content, there can be considerable sedimentation and bleed water. If sedimentation and bleeding do occur, there will be a gradient of properties through the paste, as the effective $w / \mathrm{cm}$ decreases with depth. Therefore, mixtures were also made with a $0.40 \mathrm{w} / \mathrm{cm}$ ratio so that comparisons could be made to systems for where there should have been relatively little bleeding. The binder formulations were either ordinary portand cement or a mixture of portland cement, fly ash, and slag in the proportions of 10:45:45, respectively. The mixtures are denoted by the $w / \mathrm{cm}$ (60/40), the use of a surrogate waste solution (0: NO / 1: YES), and the binder composition (100: OPC / 055: cement+fly ash+slag). The exception is that results are not given for the 40/60-0-055 mixtures.

The composition of the surrogate waste solution (SWS) was made to be as close to that used by Dixon et al. [3] as possible. The binder materials were the same as those used by SRNL, and the oxide analysis of the binders was previously reported by Harbour et al. [4]. The portland cement was an ASTM Type I, and the slag was almost entirely glassy.

The fly ash was also analyzed at NIST using X-ray powder diffraction $(\mathrm{Cu} \mathrm{K} \alpha$ target) to identify and quantify the crystalline mineral composition, and the results are shown in Table $\mathbf{1}$ below. The primary crystalline phases are mullite and quartz.

Table 1. Fly ash mineral phase composition as determined by X-ray powder diffraction and Rietveld analysis.

\begin{tabular}{|l|c|l|}
\hline Phase (XRD) & Mass Fraction (\%) & $\begin{array}{l}\text { Assumed Chemical } \\
\text { Composition }\end{array}$ \\
\hline Mullite & $18.3 \pm 0.4$ & $\left(\mathrm{~A}_{2} \mathrm{O}_{3}\right)_{2}\left(\mathrm{SiO}_{2}\right)$ \\
\hline Quartz & $7.3 \pm 0.4$ & $\mathrm{SiO}_{2}$ \\
\hline Hematite & $2.2 \pm 0.1$ & $\mathrm{Fe}_{2} \mathrm{O}_{3}$ \\
\hline Magnetite & $1.0 \pm 0.0$ & $\left(\mathrm{Fe}_{3} \mathrm{O}_{4}\right)$ \\
\hline Amorphous & $71.2 \pm 0.8$ & \\
\hline
\end{tabular}

The fresh pastes were subjected to sealed curing conditions, to the extent possible. Each mixture was cast into smaller $25 \mathrm{~mm}$ diameter, $25 \mathrm{~mm}$ tall, cylindrical plastic molds (for thermogravimetric analysis and XRD analysis) and into larger $50 \mathrm{~mm}$ diameter, $100 \mathrm{~mm}$ tall cylinder plastic molds (for pore solution analysis). The molds were sealed in plastic bags. After $24 \mathrm{~h}$, the smaller samples were demolded and placed into airtight plastic jars; the larger samples remained in the plastic cylinders, within the sealed plastic bags. All the specimens were stored at $25^{\circ} \mathrm{C}$ until the time of testing. The $w / \mathrm{cm}=0.60$ pastes were rotated (at approximately 1 rotation every $10 \mathrm{~s}$ ) during the first $24 \mathrm{~h}$ to minimize the effects of bleeding. The pore solution was extracted from cast $50 \mathrm{~mm}$ diameter cylinders (100 mm long) that were pressed an in-house device made from high strength steel and flushed with nitrogen to avoid carbonation [5]. 


\section{Results}

\subsection{Thermogravimetric Analysis (TGA)}

The portlandite content of the OPC mixtures was estimated using the thermogravimetric analysis (TGA) data, the result of which was used as the "internal standard" for the quantitative XRD analysis, and the results are given in Table 2.

Table 2. Portlandite mass fraction, as determined by TGA analysis, for the four portland cement mixtures. The uncertainty represents the measurement uncertainty having a coverage factor of one standard deviation.

\begin{tabular}{|l|l|l|l|l|}
\hline Age & $\mathbf{4 0 - 0 - 1 0 0}$ & $\mathbf{6 0 - 0 - 1 0 0}$ & $\mathbf{4 0 - 1 - 1 0 0}$ & $\mathbf{6 0 - 1 - 1 0 0}$ \\
\hline $1 \mathrm{w}$ & $0.1321 \pm 0.0003$ & $0.1350 \pm 0.0004$ & $0.1050 \pm 0.0028$ & $0.1146 \pm 0.0000$ \\
\hline $2 \mathrm{w}$ & $0.1375 \pm 0.0005$ & $0.1502 \pm 0.0007$ & $0.1081 \pm 0.0016$ & $0.1224 \pm 0.0006$ \\
\hline $4 \mathrm{w}$ & $0.1350 \pm 0.0003$ & $0.1568 \pm 0.0006$ & $0.1248 \pm 0.0013$ & $0.1416 \pm 0.0009$ \\
\hline $8 \mathrm{w}$ & $0.1433 \pm 0.0004$ & $0.1502 \pm 0.0004$ & $0.1370 \pm 0.0009$ & $0.1458 \pm 0.0008$ \\
\hline
\end{tabular}

The TGA data for the $0.60 \mathrm{w} / \mathrm{cm}$ OPC and water mixture, and the $0.60 \mathrm{w} / \mathrm{cm}$ mixture composed of the ternary blend and the SWS are shown in Figure 1. The relative mass loss $(\mu)$ was defined as the ratio of the mass $(m)$ at temperature $T$ to the initial mass: $\mu=m(T) / m_{0}$. The OPC and water mixture exhibits a portlandite decomposition peak near $450{ }^{\circ} \mathrm{C}$, and a barely perceptible limestone calcination peak near $650^{\circ} \mathrm{C}$.
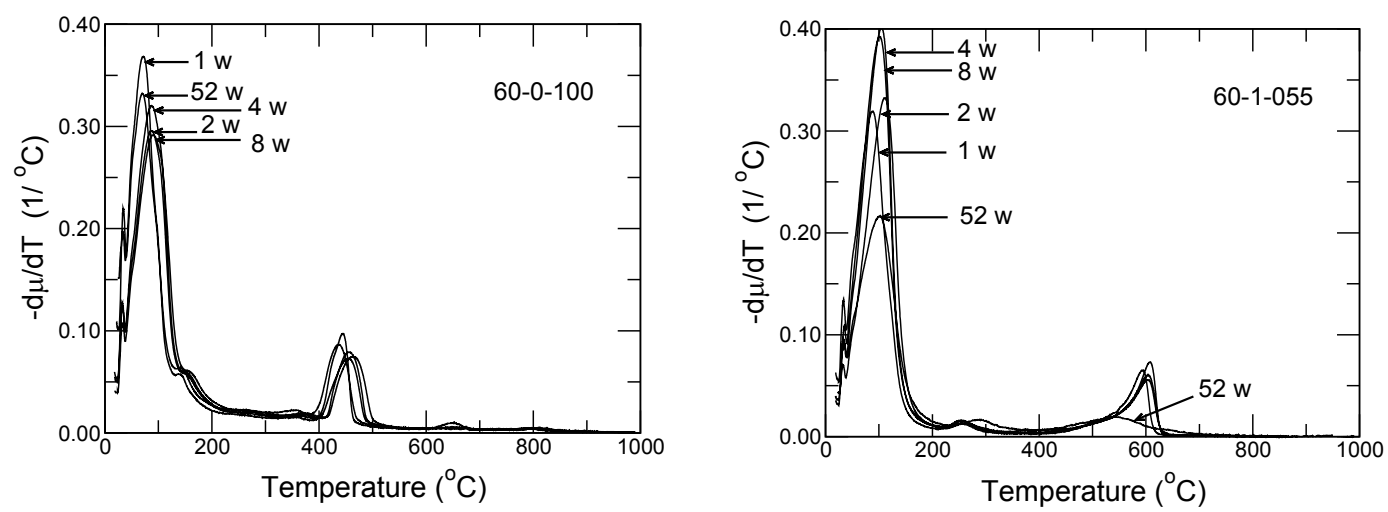

Figure 1. Differential relative mass loss $(-\mathrm{d} \mu / \mathrm{d} T)$ as a function of temperature $\left({ }^{\circ} \mathrm{C}\right)$ for the $w / \mathrm{cm}=0.60$ pastes: OPC and water mixture (left); and blended binder and SWS system (right). Each line corresponds to a different age: $1 \mathrm{w}, 2 \mathrm{w}, 4 \mathrm{w}, 8 \mathrm{w}$, and $52 \mathrm{w}$.

For the systems made with SWS, there is a significant peak located near $600{ }^{\circ} \mathrm{C}$ corresponding to nitratine (sodium nitrite) decomposition, which was consistent with reported decomposition temperatures for nitratine [6], and was confirmed by X-ray diffraction data analysis that is discussed below. 


\subsection{Quantitative X-ray Diffraction}

The X-ray powder diffraction samples were (approx.) $2 \mathrm{~mm}$ thick disks cut from the smaller cylindrical samples, and the tested surface was gently polished with a 600-grit abrasive paper. During the measurement, the sample was rotated to maximize the sampling area. The estimated portlandite composition from the TGA analysis was used as an internal standard for the systems made with only portland cement, and the mixtures composed of blended cements were made with corundum as the internal standard. The XRD scans for the $0.60 \mathrm{w} / \mathrm{cm}$ system made with OPC and water, and the blended system made with SWS, are shown in Figure 2, and are indicative of the results.

The most prominent peaks in the ordinary portland cement pastes are the portlandite peaks, the largest of which are near $18^{\circ} 2 \theta$ and $35^{\circ} 2 \theta$. The other prominent peaks are from the corundum. Also, over time, the hemicarbonate peak decreases and the monocarbonate peak height increases. Although the monocarbonate peak and the hemicarbonate peak (both very close to $12^{\circ} 2 \theta$ ) appear in both of these mixtures, the effect of the SWS is to create a broadened peak that over the individual peaks.

The most prominent peaks in Figure 2 for the 60-1-055 sample made with SWS are the corundum, quartz, and nitratine peaks. The higher glass content of these specimens is evident by the more prominent "hump" between $20^{\circ} 2 \theta$ and $35^{\circ} 2 \theta$. Moreover, with respect to OPC mixtures, the structure of the peaks below $12^{\circ} 2 \theta$ has changed in character: the hemicarbonate and monocarbonate peaks have become one broadened peak; although this peak location is consistent with tobermorite, there is no independent evidence for the existence of tobermorite. An extension of the scan angle down to $5^{\circ} 2 \theta$ (uppermost scan on the left side of Figure 2) reveals yet another "peak". This peak near $6^{\circ} 2 \theta$ has not been identified, and further study is needed.

To investigate the origin of the nitratine, an SWS sample was first analyzed using a rapid (10 minute) XRD scan, followed by the slower scan used previously. There were no nitratine peaks observed in the rapid scan, but appeared in the slower scan, typical of the other results. The conclusion was that the nitratine precipitated at the surface of the sample during the measurement. Based on this assumption, the mass fraction of nitratine was omitted from the Rietveld analysis.
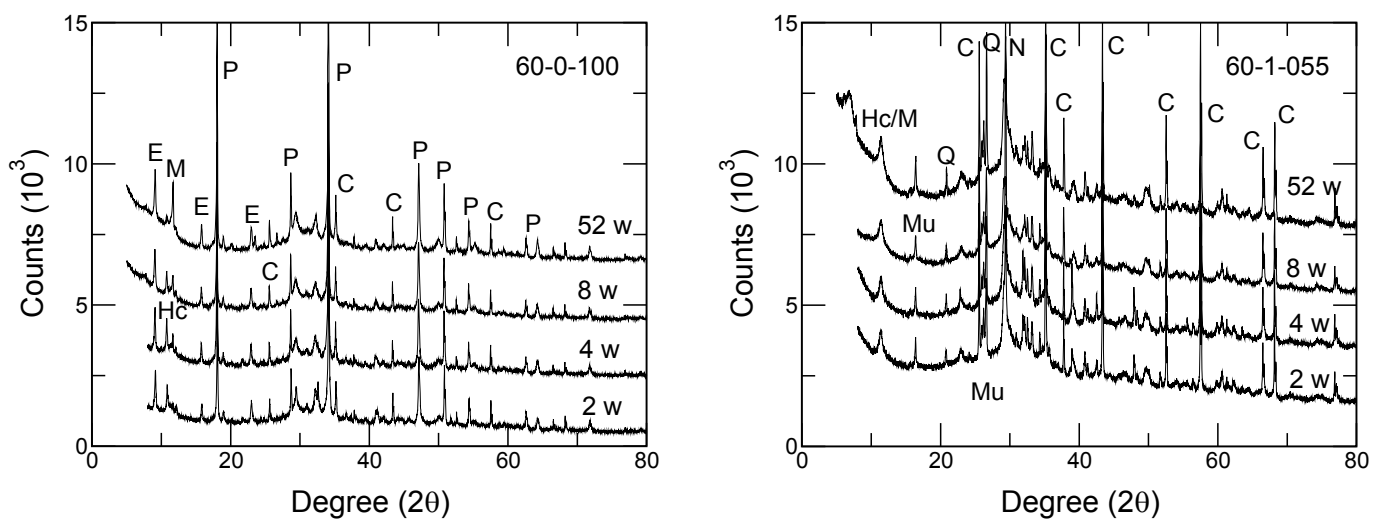

Figure 2. X-ray powder diffraction data showing counts as a function of angle $2 \theta$ for the $w / \mathrm{cm}=0.60$ pastes: OPC and water mixture (left); and blended binder and SWS system (right). Data are offset for comparison purposes, and sample age is labeled. Peaks: P-portlandite; C-corundum; Eettringite; M-monocarbonate; Hc-hemicarbonate; Q-quartz; N-nitratine; $\mathrm{Mu}-$ mullite; $\mathrm{Hc} / \mathrm{M}-$ (broadened) hemicarbonate and monocarbonate peaks.

The results of the Rietveld analyses are shown in Table 3 and Table 4 below. One important observation is that the phases that were identified are commonly seen in different types of 
cementitious materials that have been studied in the past. Another important observation is the extent of sulfate hydration phases in the saltstone mixtures. There is no evidence for significant sulfate mineral phases, even though the "mix water" contained a significant quantity of sulfate. It is quite likely that the high $\mathrm{pH}$ (which suppresses the calcium and aluminum concentrations in the pore solution), suppressed ettringite and monsulfate formation.

Table 3. Results of Rietveld analyses for the $0.40 \mathrm{w} / \mathrm{cm}$ mixtures at different ages in weeks (w). The values reported are the mass fractions, and the numbers in parentheses represent the uncertainty (one standard deviation) in the last two digits.

\begin{tabular}{|c|c|c|c|}
\hline Mineral Phase & $40-0-10052 \mathrm{w}$ & $40-1-10012 w$ & $40-1-05552 w$ \\
\hline Alite & $0.0201 \quad(21)$ & $0.0576 \quad(27)$ & $0.0163 \quad(17)$ \\
\hline Belite & 0.0164 & 0.0285 & 0.0044 \\
\hline \multicolumn{4}{|l|}{ Aluminate } \\
\hline Ferrite & 0.0697 & 0.0532 & 0.0082 \\
\hline Portlandite & 0.1433 & 0.1222 & \\
\hline Ettringite & 0.0730 & 0.0117 & \\
\hline Hemicarbonate & 0.0172 & 0.0027 & 0.0113 \\
\hline Monocarbonate & 0.0754 & 0.0109 & 0.0220 \\
\hline Corundum & & & 0.0449 \\
\hline Quartz & & & 0.0270 \\
\hline Mullite 2:1 & & & 0.0569 \\
\hline Amorphous & 0.5849 & 0.7268 & 0.8470 \\
\hline
\end{tabular}

Table 4. Results of Rietveld analyses for the $0.60 \mathrm{w} / \mathrm{m}$ mixtures at different ages in weeks (w). The values reported are the mass fractions, and the numbers in parentheses represent the uncertainty (one standard deviation) in the last two digits.

\begin{tabular}{|c|c|c|c|c|c|c|}
\hline \multirow{2}{*}{$\begin{array}{l}\text { Mineral Phase } \\
\text { Alite }\end{array}$} & \multicolumn{2}{|c|}{$60-0-10052$ w } & \multicolumn{2}{|c|}{$60-1-10016 w$} & \multicolumn{2}{|c|}{$60-1-05552 w$} \\
\hline & 0.0163 & $(42)$ & 0.0231 & (38) & 0.0108 & $(18)$ \\
\hline Belite & & & 0.0110 & $(32)$ & 0.0057 & $(72)$ \\
\hline \multicolumn{7}{|l|}{ Aluminate } \\
\hline Ferrite & 0.0580 & (59) & 0.0226 & $(45)$ & 0.0030 & (23) \\
\hline Portlandite & 0.1395 & (40) & 0.1327 & (19) & & \\
\hline Ettringite & 0.0829 & (34) & & & & \\
\hline Hemicarbonate & 0.0139 & (12) & & & 0.0107 & (16) \\
\hline Monocarbonate & 0.0917 & (42) & 0.0180 & (34) & 0.0149 & (39) \\
\hline Corundum & 0.0471 & (19) & 0.0394 & $(65)$ & 0.0890 & (46) \\
\hline Quartz & & & & & 0.0153 & (10) \\
\hline Mullite 2:1 & & & & & 0.0424 & $(27)$ \\
\hline Amorphous & 0.5505 & $(101)$ & 0.7886 & $(101)$ & 0.8872 & (104) \\
\hline
\end{tabular}

\subsection{Pore Solution Analysis}

The results from the pore solution analyses of the OPC pastes made with water appear in Table 5 and Table 6. The limited number of observations from the $0.40 \mathrm{w} / \mathrm{cm}$ OPC paste is due, in part, to the limited ability to extract useable samples from these relatively low $w / \mathrm{cm}$ systems. By comparison, the $0.60 \mathrm{w} / \mathrm{cm}$ OPC pastes yielded useable samples up to 113 days of hydration.

The apparent fluctuating sulfur concentrations in the 60-0-100 system is attributed to random variation, or merely a spurious result for the 28-day sample. 
Table 5. Pore solution composition of the $0.40 \mathrm{w} / \mathrm{cm}$ paste made with only portland cement; numbers in parentheses indicate one standard deviation of uncertainty.

\begin{tabular}{|l|l|l|}
\hline & \multicolumn{2}{|c|}{$40-0-100\left(\mathrm{mmol} / \mathrm{kg}_{\mathrm{w}}\right)$} \\
\hline Element & 7 days & $\mathbf{1 6}$ days \\
\hline $\mathrm{K}$ & $463.3(2.8)$ & $407.2(1.7)$ \\
\hline $\mathrm{Na}$ & $141.6(1.3)$ & $167.35(0.86)$ \\
\hline $\mathrm{S}$ & $12.48(0.42)$ & $14.41(0.04)$ \\
\hline $\mathrm{Ca}$ & $3.63(0.11)$ & $1.924(0.023)$ \\
\hline $\mathrm{Al}$ & $0.079(0.005)$ & $0.0910(0.0015)$ \\
\hline
\end{tabular}

Table 6. Pore solution composition of the $0.60 \mathrm{w} / \mathrm{cm}$ paste made with only portland cement; numbers in parentheses indicate one standard deviation of uncertainty.

\begin{tabular}{|l|l|l|l|l|}
\hline & \multicolumn{4}{|c|}{$60-0-100\left(\mathrm{mmol} / \mathrm{kg}_{\mathrm{w}}\right)$} \\
\hline Element & 8 days & 16 days & 28 days & 113 days \\
\hline $\mathrm{K}$ & $262.1(3.0)$ & $230.1(1.8)$ & $250.6(1.5)$ & $281.1(1.2)$ \\
\hline $\mathrm{Na}$ & $73.74(0.47)$ & $98.05(0.92)$ & $169.32(0.99)$ & $101.77(0.14)$ \\
\hline $\mathrm{S}$ & $3.24(0.11)$ & $4.327(0.078)$ & $8.11(0.21)$ & $4.194(0.057)$ \\
\hline $\mathrm{Ca}$ & $3.112(0.026)$ & $2.396(0.026)$ & $2.761(0.027)$ & $2.765(0.041)$ \\
\hline $\mathrm{Al}$ & $0.069(0.002)$ & $0.0637(0.0003)$ & $0.0141(0.0019)$ & $0.0752(0.0018)$ \\
\hline $\mathrm{Mg}$ & & & $0.0085(.0001)$ & \\
\hline
\end{tabular}

The results from the pore solution analyses of the blended cement systems and SWS appear in Table 7 and Table 8. For these samples, the challenge in collecting usable samples was the converse of the OPC pastes. The solid microstructure developed sufficiently slowly that useable samples could not be obtained until there was sufficient mechanical strength to resist the entire sample from flowing through the outlet tube on the die. For the $0.40 \mathrm{w} / \mathrm{cm}$ waste forms, usable samples were not attainable until after $14 \mathrm{~d}$ hydration, and the $0.60 \mathrm{w} / \mathrm{cm}$ waste forms did not yield usable samples until after $90 \mathrm{~d}$ hydration. The advantage of this slower microstructural development was that pore solution samples could be obtained at later ages for comparison to XRD and TGA results. In the case of the $0.60 \mathrm{w} / \mathrm{cm}$ waste form, samples were obtained out past one year of hydration.

To ensure that no sulfur was being liberated by the acid dilution (by conversion to hydrogen sulfide gas), some samples were diluted with de-ionized water prior to analysis, for comparison to the samples diluted with nitric acid $\left(\mathrm{HNO}_{3}\right)$.

Table 7. Pore solution composition of the $0.40 \mathrm{w} / \mathrm{cm}$ paste made with fly ash, slag, and surrogate waste solution; numbers in parentheses indicate one standard deviation of uncertainty.

\begin{tabular}{|l|l|l|l|l|}
\hline & \multicolumn{4}{|c|}{$40-1-055\left(\mathrm{mmol} / \mathrm{kg}_{\mathrm{w}}\right)$} \\
\hline Element & 14 days & 34 days (HNO3) & 34 days (DI Water) & 86 days \\
\hline $\mathrm{K}$ & $186.1(2.5)$ & $211.4(3.8)$ & $198.5(1.9)$ & $238.9(4.9)$ \\
\hline $\mathrm{Na}$ & $2482 .(46)$. & $3380 .(48)$. & $3478 .(63)$. & $3284 .(16)$. \\
\hline $\mathrm{S}$ & $167.7(1.3)$ & $181.0(2.0)$ & $186.5(3.9)$ & $197.4(6.4)$ \\
\hline $\mathrm{Ca}$ & $0.335(0.006)$ & $0.151(.002)$ & $0.179(.005)$ & $0.205(0.002)$ \\
\hline $\mathrm{Al}$ & - & & & \\
\hline $\mathrm{Si}$ & & $88.7(1.5)$ & $90.78(0.37)$ & \\
\hline
\end{tabular}


Table 8. Pore solution composition of the $0.60 \mathrm{w} / \mathrm{cm}$ paste made with fly ash, slag, and surrogate waste solution; numbers in parentheses indicate one standard deviation of uncertainty.

\begin{tabular}{|l|l|l|l|l|l|}
\hline & \multicolumn{5}{|c|}{ 60-1-055 (mmol $\left./ \mathrm{kg}_{\mathrm{w}}\right)$} \\
\hline Element & 91 days & $\begin{array}{l}\text { 126 days } \\
\text { (HNO3) }\end{array}$ & $\begin{array}{l}\text { 126 days } \\
\text { (DI Water) }\end{array}$ & $\begin{array}{l}\text { 391 days } \\
\text { (HNO3) }\end{array}$ & $\begin{array}{l}\text { 391 days } \\
\text { (DI Water) }\end{array}$ \\
\hline $\mathrm{K}$ & $152.4(6.3)$ & $199.4(1.7)$ & $198.13(.82)$ & $235.88(.81)$ & $237.66(.58)$ \\
\hline $\mathrm{Na}$ & $3267 .(30)$. & $3260 .(40)$. & $3311 .(44)$. & $3287 .(45)$. & $3381 .(79)$. \\
\hline $\mathrm{S}$ & $172.0(7.0)$ & $186.2(1.4)$ & $201.8(1.3)$ & $226.6(2.1)$ & $245.4(1.6)$ \\
\hline $\mathrm{Ca}$ & $1.154(0.009)$ & $0.546(0)$ & $0.262(.003)$ & $1.67(.11)$ & $0.195(.003)$ \\
\hline $\mathrm{Al}$ & - & & & & \\
\hline $\mathrm{Si}$ & & $128.90(.35)$ & $139.11(.22)$ & $78.73(.29)$ & $85.31(.23)$ \\
\hline
\end{tabular}

There were two notable observations about the elemental concentration. The sodium concentration in pore solution of all the mixtures made with SWS was considerably lower than the more than $5 \mathrm{~mol} / \mathrm{kg}_{\mathrm{w}}$ sodium concentration in the SWS solution. The lower than expected concentration may be due to a greater than expected amount of sodium binding in the calcium silicate hydrate $(\mathrm{C}-\mathrm{S}-\mathrm{H})$. This is plausible because the alkali binding increases with increasing cement replacement (resulting in lower $\mathrm{Ca} / \mathrm{Si}$ molar ratios in the $\mathrm{C}-\mathrm{S}-\mathrm{H}$ ) [7], and there are no data on binding at these sodium concentrations. By contrast, the silicon concentration was consistent with thermodynamic modeling prediction of a relatively significant silicon concentration in the pore solution. Also, the water and acid dilutions resulted in comparable sulfur concentrations, validating the accuracy of the acid dilution results.

\subsection{Discussion}

As expected, the blended binder systems (40-1-055 and 60-1-055) contained no measureable portlandite. This is to be expected because, in the absence of a source of additional calcium, the alumina and silica in the fly ash and slag will consume the calcium in the portlandite (created by the portland cement) to create additional C-S-H.

This precipitation of nitratine is consistent with the high concentration of nitrates in the surrogate waste solution, and is consistent with its observation in TGA samples at temperatures above $500^{\circ} \mathrm{C}$. As the hydration reactions consume water, the concentration of sodium nitrate is brought very close to its solubility limit, such that the small amount of water lost from exposure to the room air upon cutting the specimen is sufficient to precipitate nitratine on the surface of the sample, which is where XRD detection is most sensitive.

There are two important points of comparison between the ordinary portland cement paste mixtures and the blended binders with SWS. In the $0.40 \mathrm{w} / \mathrm{cm}$ ordinary portland cement paste (40-0$100)$, the combined mass fraction of the hemicarbonate, monocarbonate, and ettringite phases is approximately $12.5 \%$ after 12 weeks of hydration. In the $0.40 \mathrm{w} / \mathrm{cm}$ pastes containing both blended binders and SWS (40-1-055), the same total was less then $2.5 \%$, and there was no ettringite detected. In the $0.60 \mathrm{w} / \mathrm{cm}$ ordinary portland paste (60-0-100), the same sum was more than $17 \%$, while in the $0.60 \mathrm{w} / \mathrm{cm}$ paste containing both blended binders and SWS (60-1-055) the sum was below $2 \%$, and there was no ettringite detected. Therefore, although the SWS was contributing considerable sulfate to the mixture, the overall chemistry was suppressing the formation of sulfate mineral phases.

The pore solution analysis bears this out. The sulfur content of the pore solution of the ordinary portland cement 40-0-100 specimen was approximately $15 \mathrm{mmol} / \mathrm{kg}_{\mathrm{w}}$, and the sulfur content of the blended binder and SWS 40-1-055 specimen pore solution was nearly $200 \mathrm{mmol} / \mathrm{kg}_{\mathrm{w}}$. This increase is consistent with having additional sulfur in the SWS and the simultaneous absence of sulfurbearing minerals being formed during hydration. For the $0.60 \mathrm{w} / \mathrm{cm}$ specimens, the corresponding 
difference was more dramatic. The sulfur content of the pore solution of the ordinary portland cement 60-0-100 specimen was less than $10 \mathrm{mmol} / \mathrm{kg}_{\mathrm{w}}$, and the sulfur content of the blended binder and SWS 60-1-055 specimen pore solution reached nearly $250 \mathrm{mmol} / \mathrm{kg}_{\mathrm{w}}$. For the OPC systems, the decrease in sulfur with increasing $w / \mathrm{cm}$ is because the cement supplies the sulfur. For the SWS systems, the higher $w / \mathrm{cm}$ system has less chemically bound water, resulting in a higher residual sulfur concentration.

After three months of hydration, the type and quantity of mineral phases appear to be stable. No unexpected phases are forming, and the quantity of existing minerals is changing gradually. Moreover, the types of mineral phases observed are also commonly found in typical blended cement systems using in construction.

\section{Conclusion}

In general, the hydrated phases and pores solution composition of saltstone grouts is similar to what one might expect for these systems. Despite the uniqueness of the binder proportions and the concentrated solution used as the mix water, the observed phases, and their proportions, were not significantly different from what is observed in an analysis of an ordinary portland cement paste made with water.

The most notable difference between the ordinary portland cement pastes and the synthetic saltstone was the absence of ettringite, and the decreased production of hemicarbonate and monocarbonate, even after one year of hydration. The pore solution chemistry of the saltstone, which is dominated by the contribution of the SWS, appears to suppress the formation of sulfatebearing mineral phases, despite the contribution of additional sulfate in the SWS. Moreover, although solid sodium nitrate (nitratine) was detected in both the XRD and the TGA measurements, it was determined that these observations were the result of an experimental artifact.

The sodium concentration in the pores solution was less than expected, most probably because the degree of sodium binding (into the hydration phases) has never been quantified at these very high concentrations, and for the type of C-S-H formed by these blended systems. Moreover, after one year of hydration, the mineral phases that were detected are found in blended cement concretes and these mineral phases appear to be relatively stable.

\section{References}

1. A. Bradford, D. Esh, A. Ridge, M. Thaggard, R. Whited, S. Treby, S. Flanders, and L.W. Camper, "U.S. Nuclear Regulatory Commission Technical Evaluation Report for the U.S. Department of Energy Savannah River Site Draft Section 3116 Waste Determination for Salt Waste Disposal," Technical Report (U.S. Nuclear Regulatory Commission, Washington, D.C., 2005).

2. K. Dixon, J. Harbour, and M. Phifer, "Hydraulic and Physical Properties of Saltstone Grouts and Vault Concretes," SRNL-STI-2008-00421, Savannah River National Laboratory (November 2008).

3. K. Dixon, J. Harbour, and M. Phifer, "Hydraulic and physical properties of saltstone grouts and vault concretes." Savannah River National Laboratory, SRNL-STI-2008-00421 (2008).

4. J.R. Harbour, E.K. Hansen, T.B. Edwards, V.J. Williams, R.E. Eibling, D.R. Best, and D.M. Missimer, "Characterization of Slag, Fly Ash and Portland Cement for Saltstone," WSRC-TR2006-00067, Savannah River National Laboratory, Aiken, SC (February 2006).

5. R.S. Barneyback Jr. and S. Diamond, Cement and Concrete Research, 11, 279-285 (1981).

6. B.D. Bond and P.W.M. Jacobs, J. Chem. Soc. A, 1265-1268 (1966).

7. S.-Y. Hong and F.P. Glasser, Cement and Concrete Research, 29, 1893-1903 (1999). 